\title{
EMERGENCE OF CARBAPENEM RESISTANCE AMONG EXTENDED SPECTRUM BETA-LACTAMASE ISOLATE OF Escherichia coli FROM CLINICAL SPECIMENS IN A TERTIARY HOSPITAL, NIGERIA
}

\author{
AKUJOBI C.N. AND EZEANYA C.C.* \\ Department of Medical Microbiology and Parasitology, Faculty of Medicine, Nnamdi Azikiwe University, Nnewi Campus, Nigeria. \\ ${ }^{*}$ Corresponding Author: Email- chi_chi34@yahoo.com
}

Received: January 10, 2013; Accepted: March 01, 2013

\begin{abstract}
Extended-spectrum $\beta$-lactamases (ES $\beta L s)$ are a rapidly evolving group of $\beta$-lactamases which share the ability to hydrolyze thirdgeneration cephalosporins and aztreonam yet are inhibited by clavulanic acid. In this study, the aim was to determine the susceptibility of ES $\beta L$ producing clinical isolates of Escherichia coli across various antimicrobial agents according to the Clinical Laboratory Standard Institute (CLSI) new breakpoints. Sixty five clinical isolates of Escherichia coli were collected from a Tertiary Hospital in Nigeria of which forty six ESBL -producing isolates emerged. Presence of ES $\beta L$ was determined by double- disk synergy test, DNA extraction and amplification of ES $\beta L$ genes- blasнv, blaтем, blactх-м by Polymerase Chain Reaction. Susceptibility of the ESßL-producing isolates was determined by the CLSI agar diffusion method. Utilizing the CLSI new breakpoints, $76.09 \%, 73.91 \%, 73.91 \%$ and $63.04 \%$ were resistant to Cefotaxime, Ceftazidime, Aztreonam and Cefepime respectively. While, $19.6 \%, 15.2 \%, 21.7 \%$ and $40 \%$ were susceptible to Cefotaxime, Ceftazidime, Aztreonam and Cefepime respectively. Furthermore, though a significant number of ES $\beta L$-producing isolates were susceptible to carbapenem; ES $\beta L$ isolates that harboured the blasнv, blaтем, blaстх-м genes showed resistance to carbapenem. Thus, carbapenem-resistant ES $\beta$ L-producing isolates emerged from this study. In conclusion, Nigeria is a developing country affected by the spread of bacterial strains harbouring ES $\beta L$ and with the emergence of carbapenem resistance; it is certain to create significant therapeutic problems as carbapenem is the drug of choice for serious infections caused by ES $\beta L$-producing Escherichia coli.
\end{abstract}

Keywords- Extended-spectrum $\beta$-lactamases (ES $\beta L S)$, Carbapenem-resistance, Clinical specimens, Escherichia coli isolates

Citation: Akujobi C.N. and Ezeanya C.C. (2013) Emergence of Carbapenem Resistance among Extended Spectrum Beta-lactamase Isolate of Escherichia coli from Clinical Specimens in a Tertiary Hospital, Nigeria. International Journal of Microbiology Research, ISSN: 0975-5276 \& EISSN: 0975-9174, Volume 5, Issue 2, pp.-367-370. DOI : 10.9735/0975-5276.5.2.367-370.

Copyright: Copyright@2013 Akujobi C.N. and Ezeanya C.C. This is an open-access article distributed under the terms of the Creative Commons Attribution License, which permits unrestricted use, distribution and reproduction in any medium, provided the original author and source are credited.

\section{Introduction}

Beta lactamases ( $\beta$ Ls) which are enzymes hydrolyzes $\beta$ lactam antibiotics like penicillins, cephalosporins, carbapenems and monobactems [1]. Third-generation cephalosporins(3GCs) which are extended spectrum cephalosporins were thought to be resistant to hydrolysis by beta lactamases. But, in mid 1980s, it became evident that a new type of beta lactamase emerged which could also hydrolyze the extended spectrum cephalosporins. These are termed "extended spectrum beta lactamases" (ESßLs). These enzymes result from mutations of Temorina and Sulf hydryl variable (SHV) enzymes, usually plasmid mediated [2]. These and other newly detected $\beta$ - lactamases (for example CTX-M) hydrolyze $\beta$-lactam antibiotics containing the oxymino side-chain. CTX-M preferentially hydrolyzes cefotaxime. Due to the changes in amino acids sequences they are divided into five groups. They are found mostly in the Enterobacteriaceae family [3]. Some derivatives of TEM and SHV are not inhibited by clavulanic acid thus are known as inhibitor resistant TEM (IRTs) [4].

ESßLs hydrolyzes penicillins, narrow-spectrum as well as thirdgeneration cephalosporins, and monobactems. The ES $\beta L s$ have hydrolysis rates for ceftazidime, cefotaxime, or aztreonam (aminothiazoleoxime $\beta$-lactam antibiotics). They are inhibited by clavulanic acid. In general, the fourth-generation cephalosporin, cefepime, is clinically less useful against ES $\beta L$-producing organisms [5].

The presence of ESßLS carries tremendous clinical significance [6]. The ES $\beta L s$ are frequently plasmid encoded. Plasmids responsible for $E S \beta L$ production frequently carry genes encoding resistance to other drug classes such as the aminoglycosides. Therefore, antibiotic options in the treatment of ESBL-producing organisms are extremely limited [7]. Carbapenems are the treatment of choice for serious infections due to ES $\beta L$-producing organisms, yet carbapenem-resistant isolates have recently been reported [8]. ESBLproducing organisms may appear susceptible to some extendedspectrum cephalosporins. Consequently, treatment with such antibiotics has resulted to high failure rates [9].

For ESBL-producing bacteria, there is a drastic rise of MIC for extended-spectrum cephalosporins as the inoculum is increased beyond that used in routine susceptibility testing. Same isolates may test susceptible at the standard inoculum and resistant at a higher 
inoclum [10]. Therefore, false-negative results may possibly occur with both screening and confirmatory tests when lower inocula are used [11].

At present, however, organizations such as the Clinical and Laboratory Standards Institute (formerly the National Committee for Clinical Laboratory Standards) provide guidelines for the detection of ES $\beta$ Ls in Klebsiellae and Escherichia coli (E. coli). In common to all $E S \beta L$ detection methods is the general principle that the activity of extended-spectrum cephalosporins against ES $\beta$ L-producing organisms will be enhanced by the presence of clavulanic acid [12]. ES $\beta$ Ls represent an impressive example of the ability of gramnegative bacteria to develop new antibiotic resistance mechanisms in the face of the introduction of new antimicrobial agents [13]. There are no documented reports yet on the emergence of carbapenem resistance among extended spectrum beta-lactamase clinical isolate of $E$. coli from Nigeria. Therefore, this work provides a first report on the emergence of carbapenem resistance among extended spectrum beta-lactamase clinical isolate of $E$. coli from Nigeria.

\section{Materials and Methods}

\section{Study Area}

The study area was a tertiary hospital which is a referral centre for many hospitals and clinics in neighbouring states - Imo, Abia and Delta State.

\section{Collection of Isolates}

Sixty five (65) properly identified $E$. coli isolates from five hundred clinical specimens (Urine, Semen, Wound Swab, High Vaginal Swab, Ear Swab and Sputum) in the routine bacteriology laboratory of Nnamdi Azikiwe University Teaching Hospital, Nnewi were collected for this work.

\section{Identification of Isolates}

Isolates were identified using standard conventional microbiological techniques (microscopy, biochemical testing and culturing). Pure cultures of the isolates were stored in nutrient agar slant at $4^{\circ} \mathrm{C}$ for further analysis.

\section{Determination of Extended Spectrum Beta- Lactamase}

The presence of Extended Spectrum $\beta$-lactamase (ES $\beta L)$ was determined by the Double Disk Synergy Test (DDST) for all isolates. A suspension of the test organism was prepared to turbidity equivalent to $0.5 \mathrm{McF}$ arland Standards and then an aliquot was inoculated on Muller Hinton agar plate using sterile swab stick. A disk containing Amoxicillin plus Clavulanic acid (moxclav 20/10 $\mu$ g) disc was placed centrally on the Muller- Hinton agar plate. Discs containing Ceftazidime $(30 \mu \mathrm{g})$ was placed $15 \mathrm{~mm}$ out from the edge of moxclav disc, so that its inner edge was $15 \mathrm{~mm}$ from it. The same was performed with Cefotaxime $(30 \mu \mathrm{g}), 15 \mathrm{~mm}$ from moxclav disc. Plates prepared were incubated at $35^{\circ} \mathrm{C}$, aerobically for 18-24hours; zone diameters and zone-enhancement toward moxclav disc was recorded for all the cephalosporins, as per Clinical Laboratory Standard Institute (CLSI) guidelines. Plates with negative result were further incubated at $37^{\circ} \mathrm{C}$, aerobically for 18-24 hours. E. coli ATCC 25922 and Klebsiella pneumoniae ATCC 700603 were used as negative and positive control.

\section{Antimicrobial Susceptibility Testing}

The antimicrobial agents used were: Cefotaxime $(30 \mu \mathrm{g})$,

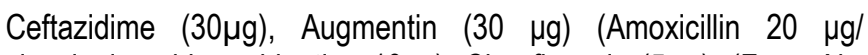

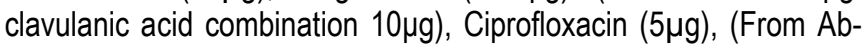
tek Biological Ltd, Liverpool, UK), Cefepime $(30 \mu \mathrm{g})$, Imipenem $(10 \mu \mathrm{g})$, Meropenem $(10 \mu \mathrm{g})$, Fosfomycin $(50 \mu \mathrm{g})$ and Aztreonam $(30 \mu \mathrm{g})$ (From Oxoid, UK). A suspension of the test organism was prepared to turbidity equivalent to $0.5 \mathrm{Mc}$ Farland standards and an aliquot was inoculated on Muller Hinton agar plate using sterile swap stick. All plates were incubated for $18-24$ hours at $37^{\circ} \mathrm{C}$ in air. Antimicrobial susceptibility test was performed on each isolate by disk diffusion method and diameter of zones of inhibition were interpreted as; Susceptible (S), Intermediate (I) and Resistant (R) as recommended by Clinical Laboratory Standard Institute, CLSI [14]. E. coli ATCC 25922 was used as control.

\section{DNA Extraction and Amplification of Extended Spectrum $\beta$ - Lactamase Genes in the Isolates using Polymerase Chain Re- action (PCR)}

Isolates producing ES $\beta$ Ls were subjected to polymerase chain reaction (PCR) targeting blasHv, blatem, blactX-m genes. Genomic DNA was extracted according to the published method of Johnson and Woodford [15].

PCR conditions were as follows: reactions were carried out in MWG thermo cycler in $25 \mu \mathrm{l}$ mixtures containing $12.5 \mu \mathrm{l}$ PCR Master Kit (From Qiagen, Hilden, Germany), 9.5 $\mu$ sterile deionized water, $200 \mu \mathrm{M}$ of dNTP, $1 \mu$ lemplate DNA and $1 \mu$ l of each oligonucleotide primer [16]. Initial denaturation at $95^{\circ} \mathrm{C}$ for $4 \mathrm{~min}$ followed by 30 cycles of denaturation at $95^{\circ} \mathrm{C}$ for $1 \mathrm{~min}$, annealing for $1 \mathrm{~min}$ and at $48^{\circ} \mathrm{C}$ for TEM, and $60^{\circ} \mathrm{C}$ for SHV, CTX-M, extension at $72^{\circ} \mathrm{C}$ for $1 \mathrm{~min}$. The final extension step was extended to $10 \mathrm{~min}$ at $72^{\circ} \mathrm{C}$ for all genes [17]. The amplified genes were seen in an electrophoretic gel. Escherichia coli 6681 containing blasHv, blactx-M and bla TEM $_{T-}$ gene were used as controls.

\section{Statistical Analysis}

Standard percentage occurrence was used for the calculations of data received. Parametric method (Two factor ANOVA using Microsoft Excel) were used for statistical analysis.

\section{Results}

From our study, Escherichia coli had highest prevalence (65 isolates) among other gram negative organisms isolated from the clinical specimens. Following detection of ES $\beta L$ isolates of Escherichia coli (46 isolates), prevalence of the enzyme across various clinical specimens showed that the ES $\beta$ L-producing isolates recovered from Sputum, Ear Swab, Semen and Endo Cervical Swab were $100 \%$ respectively [Table-1]. The susceptibility profile showed $93.5 \%$ susceptibility of the ES $\beta \mathrm{L}$-producing isolates to Meropenem, $80.4 \%$ susceptibility to Imipenem, $76 \%$ susceptibility to Fosfomycin. The resistance patterns across the antimicrobial agents are: Meropenem $(2.17 \%)$, Imipenem (6.52\%), Fosfomycin (15.22\%), Coamoxiclav (32.61\%), Cefepime (63.04\%), Ciprofloxacin (65.22\%), Aztreonam (73.91\%), Ceftazidime (73.91\%) and Cefotaxime $(76.09 \%)$. [Table-2] showed the results of percentage of intermediate pattern across the antibiotics in ESBL positive isolates. A total of $35(76 \%)$ ES $\beta$ L producing isolates showed resistance to one or more of the third generation cephalosporins and aztreonam. The resistance zone of inhibition for Cefotaxime ranged from $\leq 22 \mathrm{~mm}$, for Ceftazidime ranged from $\leq 17 \mathrm{~mm}$, for Aztreonam ranged from $\leq$ $16 \mathrm{~mm}$, for Cefepime ranged from $\leq 14 \mathrm{~mm}$. PCR amplification was performed using the primers listed in [Table-3]. It was observed that there was a relationship between ES $\beta$ L genes- blasHv, blatem, blactx 
-m genes and resistance to carbapenem with blactх-м having the highest percentage (43.48\%) [Table-4].

Table 1- Prevalence of Escherichia coli ES $\beta$ L among the clinical specimens

\begin{tabular}{|lcc|} 
Clinical Specimen & $\begin{array}{c}\text { Number of } \\
\text { E. coll isolate }\end{array}$ & $\begin{array}{c}\text { Number/Percentage of ES } \beta L \\
\text { E. colli isolates (\%) }\end{array}$ \\
\hline Urine & 30 & $22(73)$ \\
High Vaginal Swab (HVS) & 16 & $10(62.5)$ \\
Wound Swab & 7 & $2(28.6)$ \\
Sputum & 5 & $5(100)$ \\
Ear Swab & 3 & $3(100)$ \\
Semen & 3 & $3(100)$ \\
Endo Cervical Swab (ECS) & 1 & $1(100)$ \\
Total & 65 & 46 \\
\hline
\end{tabular}

Table 2- Percentage of Susceptibility, Intermediate and Resistance pattern among the ES $\beta L$ isolates across the antimicrobial agents Antimicrobial agents Susceptible (\%) Intermediate (\%) Resistant (\%) Imipenem (10

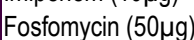

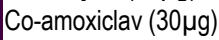
Cefepime $(30 \mu \mathrm{g})$ Ciprofloxacin $(5 \mu \mathrm{g})$ Ceftazidime $(30 \mu \mathrm{g})$ Aztreonam $(30 \mu \mathrm{g})$ Cefotaxime $(30 \mu \mathrm{g})$

$43(93.5)$
$37(80.4)$
$35(76)$
$10(21.7)$
$17(40)$
$13(28.3)$
$7(15.2)$
$10(21.7)$
$9(19.6)$

\begin{tabular}{cc}
$2(4.35)$ & $1(2.17)$ \\
$6(13.04)$ & $3(6.52)$ \\
$4(8.70)$ & $7(15.22)$ \\
$21(45.65)$ & $15(32.61)$ \\
$0(0)$ & $29(63.04)$ \\
$3(6.52)$ & $30(65.22)$ \\
$5(10.87)$ & $34(73.91)$ \\
$2(4.35)$ & $34(73.91)$ \\
$2(4.35)$ & $35(76.09)$ \\
\hline
\end{tabular}

Table 3- Primers used for amplification Primer Name Primer Sequence( $5^{1}$ to $\left.3^{1}\right)$ Size(bp) Gene Reference

\begin{tabular}{lllll} 
SWSHV-A & AAG ATC CAC TAT CGC CAG CAG & 200 & blashv & {$[15]$} \\
SWSHV-B & ATT CAG TTC CGT TTC CCA GCG G & & & \\
TEM-A & GAG TAT TCA ACA TTT CCG TGT C & 800 & blatem & {$[15]$} \\
TEM-B & TAA TCA GAG GCA CCT ATC TC & & & \\
CTX-M A & CGC TTT GCG ATG TGA AG & 550 & blactX-M & {$[15]$} \\
CTX-M B & ACC GCG ATA TCG TTG GT & & & \\
\hline
\end{tabular}

Table 4- Relationship between Antimicrobial resistance pattern and ES $\beta L$ genes among ES $\beta L$-producing isolates

\begin{tabular}{|lllll|}
\hline Antimicrobial agents & \%Resistant & \% blaTEM & $\%$ blaCTX-M & \% blaSHV \\
\hline Meropenem $(10 \mu \mathrm{g})$ & 2.17 & 0 & 2.17 & 0 \\
Imipenem $(10 \mu \mathrm{g})$ & 6.52 & 2.17 & 2.17 & 2.17 \\
Fosfomycin $(50 \mu \mathrm{g})$ & 15.22 & 4.35 & 8.7 & 2.17 \\
Co-amoxiclav $(30 \mu \mathrm{g})$ & 32.61 & 10.87 & 10.87 & 10.87 \\
Cefepime $(30 \mu \mathrm{g})$ & 63.04 & 13.04 & 32.61 & 17.39 \\
Ciprofloxacin $(5 \mu \mathrm{g})$ & 65.22 & 21.74 & 21.74 & 21.74 \\
Ceftazidime $(30 \mu \mathrm{g})$ & 73.91 & 30.43 & 10.87 & 32.61 \\
Aztreonam $(30 \mu \mathrm{g})$ & 73.91 & 21.74 & 39.13 & 13.04 \\
Cefotaxime $(30 \mu \mathrm{g})$ & 76.09 & 19.57 & 43.48 & 13.04 \\
\hline
\end{tabular}

\section{Discussion}

In this study, we found that ES $\beta$ L-producing isolates of Escherichia coli showed different patterns of resistance to various antimicrobial agents when using the new CLSI Susceptibility breakpoints. This may reflect the different abilities of ES $\beta$ Ls to hydrolyze different antimicrobial agents especially cephalosporins and aztreonam.

All ESßL-producing isolates of Escherichia coli showed resistance to Cefotaxime. The susceptibility of ES $\beta$ L-producing isolates of Escherichia coli to Ceftazidime, Cefepime and Aztreonam varied. Resistance to Cefotaxime: maybe a better marker for the presence of ES $\beta$ L than resistance to Ceftazidime. Surprisingly, $2.17 \%$ $6.52 \%$ of ES $\beta$ L-producing isolates of Escherichia coli appeared to be resistant to Meropenem and Imipenem which are carbapenemsthe treatment of choice for serious infections due to ESßLproducing organisms [18]. Though, a significant number of ES $\beta$ L- producing isolates were susceptible to carbapenems and fosfomycin. The variety profiles of susceptibility to carbapenem might be due to the combination of porin loss and $\beta$-lactamase production which results to carbapenem resistance [19]. This may explain the presence of blasнv, blatem, blactx-m genes of ES $\beta$ L harboured by the isolates.

We also observed that Imipenem resistant ES $\beta$ L -producing isolates emerged from urine and semen with more from urine. While, Meropenem resistant ES $\beta$ L-producing isolate emerged from High Vaginal Swab (HVS). All ES $\beta$ L isolates were susceptible to Meropenem except isolates from High Vaginal Swab (HVS). ES $\beta$ L isolates from urine showed resistance to all the antimicrobial agents except Meropenem. While, ES $\beta$ L isolates from High Vaginal Swab (HVS) showed resistance to all the antimicrobial agents except Imipenem. $E S \beta L$ isolates from wound swab showed the lowest resistance to the antimicrobial agents followed by ES $\beta$ L isolates from Sputum.

From our study, Fosfomycin and Co-amoxiclav may serve as suitable therapeutic option for uncomplicated infections by ES $\beta$ Lproducing E. coli. Imipenem and Meropenem could serve as suitable therapeutic options for serious infections ranging from nosocomial urinary infection to bacteremia. Although, Carbapenem, Fosfomycin and Co-amoxiclav resistant isolates emerged, resistance to these antimicrobial agents was minimal.

Further well designed clinical studies are needed to determine the efficacy of Carbapenem (Imipenem and Meropenem), Fosfomycin and Cefepime in the treatment of infections caused by ES $\beta$ Lproducing strains of Escherichia coli most especially in treating uncomplicated to serious infections such as non-bacteremic urinary infection to nosocomial infections.

\section{Conclusion}

Escherichia coli are known pathogenic organism that has caused clinically important infections which has led to sever morbidity and mortality. The presence of ES $\beta$ Ls plus carbapenem resistance will surely create significant therapeutic problems in the future. Prolong and extensive use of carbapanem in treatment of infection caused by ES $\beta$ L isolates as led to carbapenem resistant strains. Thus, heavy antibiotic use poses a risk factor for the acquisition of an ESßL-producing organism [20]. Continual alteration of antibiotic susceptibility breakpoints may become necessary but need to be carefully considered in combination with clinical data.

\section{Acknowledgment}

Thanks are owed to Dr lloduba Aghanya and Jovita Madu for their technical support and practical assistance.

Conflict of Interest- There are no conflict of interest between authors.

\section{References}

[1] Livermoore D.M. and Paterson D.L. (2006) Pocket Guide to Extended Spectrum $\beta$-lactamases, 51-62.

[2] Paterson D.L. and Bonomo R.A. (2005) Clin. Microbiol. Rev., 18, 657-686.

[3] Bradford P.A. (2001) Clin. Microbiol. Rev., 14, 933-951.

[4] Pitout J.D., Nordmann P., Kevin B., Laupland K.B. and Poirel L. (2005) J. Antimicrob. Chemother., 56, 52-59.

[5] Sanders C.C. (1996) J. Chemother., 8, 57-62.

[6] Paterson D.L., Ko W.C., Gottberg A.V., Mohapatra S., Casellas 
J.M. and Goossens H. (2004) Clin. Infect. Dis., 39, 31-37.

[7] Paterson D.L. (2000) Clin. Microbiol. Infect., 6, 460-463.

[8] Chaudhary U. and Aggarwal R. (2004) Indian J. Med. Microbiol., 22, 75-80.

[9] Nathisuwan S., Burgess D.S. and Lewis II J.S. (2001) Pharmacotherapy, 21, 920-928.

[10]Emery C.L. and Weymouth L.A. (1997) J. Clin. Microbiol., 35, 2061-2067.

[11]Queenan A.M., Foleno B., Gownley C., Wira E. and Bush K. (2004) J. Clin. Microbiol., 42, 269-275.

[12]Paterson D.L. and Yu V.L. (1999) Clin. Infect. Dis., 29, 14191422.

[13]Samaha-Kfoury J.N. and Araj G.F. (2003) British Medical Journal, 327,1209-1213.

[14]Clinical and Laboratory Standards Institute Performance Standards for Antimicrobial Susceptibility Testing (2011) Twenty-First Informational Supplement, 31(1), 44-50.

[15]Johnson A. and Woodford N. (1998) Molecular Bacteriology Protocols and Clinical Application, 24-28.

[16]Eftekhar F., Hosseini-Mazinani S.M., Ghandili S., Hamraz M. and Zamani S. (2005) Iranian J. Biotech., 3(1), 48-54.

[17]Shahcheraghi F., Nasiri S. and Noveiri H. (2009) Iranian J. Basic Med. Sci., 13(2), 230-237.

[18]Eveillard M., Schmit J.L. and Eb F. (2002) Infect. Control. Hosp. Epidemiol., 23, 155-158.

[19]Ananthan S. and Subha A. (2005) Indian J. Med. Microbiol., 23, 20-23.

[20]Lautenbach E., Patel J.B., Bilker W.B., Edelstein P.H. and Fishman N.O. (2001) Clin. Infect. Dis., 32, 1162-1171. 